\title{
DISRUPTIVE TECHNOLOGIES IN FASHION INDUSTRY
}

\author{
Jeyaraman Anandha Kumar \\ Lecturer, Department of Textile Processing, \\ G.R.G. Polytechnic College, Kuppepalayam, Sarkar Samakulam, Coimbatore, India.
}

\begin{abstract}
Fashion is one of the key industries that is currently being redefined by digital disruption. This phase of digital disruption has not been good news for traditional players in the industry. Traditional fashion companies and brands have been slow to adapt to this new shift and are feeling the heat. This change is to react to the shift from offline to online sales, which innovative digital technologies accelerated. The impact of this disruption can be seen everywhere in the fashion industry from production and supply chain to marketing and sales. Digital devices, platforms, and technologies such as smart phones, social media, advanced data analytics, artificial intelligence, and e-commerce are re-shuffling the market dynamics. This paper discusses the trends redefining how business is done in the fashion industry.
\end{abstract}

Key words- Fashion, disruption, channels, fashion retailers, wearable technology

\section{INTRODUCTION}

Fashion reflects the change in aesthetic, economic, political, cultural, and social life. Individuals and society use fashion to communicate their taste and lifestyle. The common tastes and lifestyle of society collectively form and represent the taste and lifestyle of that society. Those new emerging lifestyles are interpreted by fashion designers into fashion concepts and then translated into fashion commodities. Although the fashion industry developed first in Europe and America, today it is an international and highly globalized industry, with clothing often designed in one country, manufactured in another, and sold in a third. The fashion industry has long been one of the largest employers and it remains so in the 21st century and accounts for a significant share of world economic output. The fundamental problem in fashion industries is that the time it takes to source materials, convert them into products and move them into the market place is invariably longer than the time the customer is prepared to wait.

\section{ONLINE RETAILERS ARE WINNING}

Since traditional fashion companies have been slow to capture the online market for fashion, this gap has been filled by online-only retailers (Augello, M et al ,2016) Online-only retailers are not only providing an online platform for selling fashion products, but they are also offering a great customer experience. They are efficient in listening and understanding what the consumers want using different means, such as social media, advanced data analytics tools, and artificial intelligence. They quickly react to consumer insights gathered through digital technologies and incorporate them into their decision-making process. Therefore, without embracing digital technologies and providing what customer want fashion brands and retailers will continue to lose their share of the fashion market. (Bertola, P. and Colombi,2014)

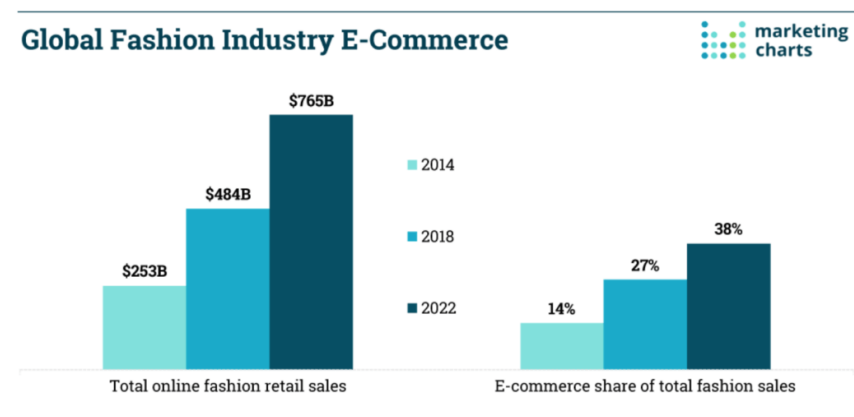

Fig 1 Global Fashion Industry and E-Commerce

\section{CHANGING CONSUMER BEHAVIOR}

Digital technologies are reshaping the expectations, behaviors, and habits of fashion consumers. Now consumers are much more empowered and play a central role in deciding when and what should be produced. Instead of going to physical stores, consumers are spending more time shopping online. (Bini, V. 2011) Particularly millennial are shifting from offline to online, to such an extent that 2 out of 3 millennial prefer to shop for fashion online fashion consumers' online-shopping habits influenced by social media. The consumer trend to use digital tools and platforms to buy fashion products does not show signs of slowing down. The online sales for fashion, particularly for apparel and footwear, will continue to increase rapidly over the coming years. If traditional fashion players want to survive, they will have to integrate new technologies, invest in adopting innovative business models, and engage consumers through different digital channels to provide an excellent shopping experience online. (Buckley, C. 2011) 


\subsection{ARTIFICIAL INTELLIGENCE}

This trend is likely to rapidly accelerate in the coming years. AI can predict fashion trends, and help fashion players in deciding when and what to sell. Advanced AI programs are capable of learning individual consumer's fashion preferences and designing items that fit the consumer's individual style.( Berg, A., et al, 2017) Many fashion retailers and brands are already using $\mathrm{AI}$ in their operations. Customer service chat bots are becoming a norm. This trend will see an increase in the use of $\mathrm{AI}$ in functions ranging from production to supply chain management to customer service. Fashion players, who don't incorporate AI into their operations, stand to lose. Artificial intelligence (AI), however, can quickly church through masses of data in order to provide useful insights into buying patterns, spending habits, and even color and style preferences. AI can tell you if historically scarlet has been a bigger seller than rust or whether narrow ties have far outpaced wider ties in sales. This data can be then used to design clothing that people really want to wear. (Teunissen, J. and Van der Voet, H. 2013)

\subsection{CUTOMISATION}

With digital data and trend analysis tools fashion retailers can personalize their offerings. Since consumers are interacting with digital tools and platforms more and more, they are also giving away a lot more data about themselves. (K. Straker, C. Wrigley, 2015) A clever use of this data is through advanced data and analytic tools. Those sophisticated tools can help fashion retailers appeal directly to the tastes of individual consumers. Instead of relying on focus groups and customer surveys, fashion retailers can collect personal data and reach out to them effectively. They can predict consumer demand through digital data collection and analysis tools. Application of advanced data tools can also help them modernize their supply chain and cut waste. Every designer knows that no two bodies are the same.Two people may theoretically wear the same size, but one may have a smaller waist and wider hips, while the other has a higher waist and lower hips. All of these factors affect how fashion fits. Smart tech allows designers to offer more variations in a single design to fit a wider variety of bodies.

\subsection{FASTER FASHION}

Other forms of disruption we see in fashion include exclusivity, faster fashion, and new channels. Numerous established brands are rethinking their business models to reflect these evolutions. For instance, some are moving away from the traditional fashion calendar and imitating the "drop" approach commonly used by street wear labels to release smaller and more frequent collections that create rarity value and elevate anticipation. This has given rise to a broader range of holiday offerings as well as the introduction of microseasons. In addition, this also allows smaller retailers to provide a greater range of offerings to their consumers, and if they find themselves with a huge hit on their hands, they can even order more and get them in the hands of their consumers before demand dies down or the competition catches up. (Barnes, L., \& Lea-Greenwood, G. 2006)

\subsection{FASHION MOVES ONLINE}

Online shopping reached a tipping point. With purchase being made online, consumers were officially doing more online shopping than in retail stores. Overall, retail stores are becoming smaller and fewer and many brands are eschewing retail stores at all. In the age of smart tech, it is now possible to build a fashion powerhouse without ever opening a physical store. (Bruce, M., Daly, L., \& Towers, N. 2004).

\subsection{SMART FASHION}

From connected jackets to smart sports apparel, clothing is quickly becoming connected to the Internet of Things (IoT).Soon, your clothing will get you into your building in the morning and may even be able to unlock and start your car. Heart rate monitors that are somewhat inefficient when worn on the wrist become finely tuned when integrated into a bra. Biofeedback on everything from your golf to your running stride is also available through smart fashion.( Christopher, M., \& Towill, D. 2001)

\subsection{WEARABLE TECHNOLOGY BEYOND THE WRIST}

For some time, the phrase "wearable technology" was synonymous with smart watches and designer-branded accessories for fitness and activity trackers, but fashion companies have started embracing technology as a component of their products. One example is the "data dress," which is a dress that is customized based on personal information gathered about the customer. By using a mobile application, information such as the local weather and daily activities is collected and used to design a dress meant to fit the individual's lifestyle. However, as discussed above with AR and VR technologies, this collection and transfer of data, including the individual's location information, must be secure and subject to well-developed privacy policies, processes, and data security measures.( Christopher, M.,et al 2004).

\section{THE CHALLENGES RETAILERS FACE}

While brick and mortar stores may struggle the most, the truth is consumers simply want more out of retailers today. Here are some challenges that retailers face in the modern world:

\subsection{Brand Loyalty Faltering}

With literally a global marketplace at their fingertips, consumers have more options to choose from than ever before. This is making brand loyalty harder and harder to come by.In addition, where consumers may have once purchased products 
from a single brand across a variety of categories, they may now mix and match their brands quite a bit more. (Cholachatpinyo, A. et al 2002)

\subsection{Multi-Channel Shopping}

The truth is, when it comes to clothing, most consumers still want to try before they buy. When it comes to the human body, size has very little bearing on fit. Finding one garment that actually looks good and fits well can be a time-consuming chore. There is little more frustrating than finally finding a garment you love only to discover the store doesn't have it in your size or the color you want. When consumers know they can quickly jump online and order it right while they are standing in the store, however, they are more likely to frequent stores that offer this option.( Doeringer, P., \& Crean, S. 2006).

\subsection{Higher Demand for a Seamless Experience}

Once consumers have had an experience with this kind of seamless shopping, they want it everywhere. Retailers that don't offer both a brick and mortar store where customers can try on apparel and a robust online shop where they can quickly order what you don't have in stock may quickly find themselves going the way of the buffalo.( Fernie, J., \& Azuma, N. 2004).

\subsection{Lack of Data Analyses}

One huge advantage that online retailers have over brick and mortar stores is data.Online retailers know exactly what customers are looking at, how long they are looking, how quickly they buy something or how many times they come back to look at it before buying. This gives online retailers a competitive advantage brick and mortar stores just don't have.Smart tech is certainly moving the fashion world forward, but this may also cause some retailers to get left behind. (Runfola, A., \& Guercini, S. 2013) Innovation is always a double-edged sword. Early adopters that jump too soon can find themselves without a market, while retailers that lag too far behind may find themselves outpaced by the competition. The savviest of retailers keep their finger on the pulse of the future and find just the right pace to move into it.

\subsection{Augmented \& Virtual Reality Driven Experience}

Imagine walking into a clothing store and being able to check a garment with your Smartphone to see if it fits and how it would look on your actual body. Home retailers are already leveraging AR and VR to help consumers see how a couch might look in their living room or if an area rug might fit in the room. With this same tech, brick and mortar retailers might actually gain back some ground from online shoppers. (Sheridan, M., et al 2006)

\begin{tabular}{ll}
\hline Company & Initiative \\
\hline Tilly's & $\begin{array}{l}\text { Tilly's, a teen surf and sports clothing retailer, offered a back-to-school } \\
\text { scavenger hunt experience that made it easier for customers to explore } \\
\text { different clothes and accessories. }\end{array}$ \\
\hline YOOX & $\begin{array}{l}\text { YOOX Net-A-Porter created an avatar called Daisy which can be } \\
\text { customized according to the user's specifications of weight, height, skin } \\
\text { color and general body shape to virtually try on clothing. Users can also } \\
\text { include a photo to create a digital avatar that resembles them. }\end{array}$ \\
\hline 3DLOOK & $\begin{array}{l}\text { 3DLOOK uses computer vision, machine learning and statistical modeling } \\
\text { to process and measure the human body from two photos from any } \\
\text { mobile device to create a real-to-life avatar. 3DLOOK won the third } \\
\text { edition of the LVMH Innovation Award in May 2019. }\end{array}$ \\
\hline ASOS & $\begin{array}{l}\text { ASOS offers app users a "catwalk experience" to see what apparel might } \\
\text { look like in real life. Shoppers can point their phone at any flat service to } \\
\text { see avatars wearing ASOS clothing walking towards them. }\end{array}$ \\
\hline Levi Strauss & $\begin{array}{l}\text { Levi Strauss installed a 3D body scanning booth at its flagship store in } \\
\text { central London, which scans shoppers' bodies to help them find better } \\
\text { fitting jeans. }\end{array}$ \\
\hline
\end{tabular}

Fig 2 Disruptive Reality Technology

(Source: Company reports/Coresight Research)

\section{CONCLUSIONS}

Digital innovations and technologies are quickly changing the fashion industry landscape. Consumers are expecting personalized shopping experiences. Online only retailers have understood this trend, and are continuously adjusting their business models and offerings. If traditional fashion retailers want to survive, they will have to adapt a consumer-centric business model by leveraging new technologies. Retailers will increasingly rely on extended reality to engage customers browsing products. Virtual models of the human form either created through 3D technology or otherwise, will progressively guide purchasing decisions. The disruptive trends in fashion industries are Autonomous last-mile delivery robots will gain more traction. Data privacy will require a more conscientious and collaborative approach as retailers walk a tightrope between data privacy and personalizationcommerce growth will boost the use of robotics to create fully automated shipping warehouses. Retailers will push the consumerization of healthcare, especially as it relates to aging. Environmental concerns will drive a proliferation of sustainable fashion initiatives and partnerships. Reality tech will continue to blur the line between digital experiences and reality.5G will finally be rolled out commercially, enabling technological advancements across the board. Voice tech development will become more brand-oriented. Banking-as-aService (BaaS) and digital payment solutions will see exceptional retailer adoption and growth. On-demand product customization and 3D printing will lead a boom in personalized offers.

\section{Acknowledgement}

The author would like to thank the chair person of GRG Institutions Dr.Nandhini Rangasamy for her constant motivation and encouragement to carry out this work. The 
author would like to thank the CEO of Fascino Dresses Mrs. Shiny Anto for sharing her views to compile this work.

\section{REFERENCES}

[1]. Augello, M., Bertola, P., Colombi, C., Iannilli, V. and Vacca, F. (2016), "Design research and sensemaking in culture intensive industries: driving innovation through a design reading of cultural evolutions", The Design Journal, Vol. 19 No. 2, pp. 155-167.

[2]. Bertola, P. and Colombi, C. (2014), "Fashion Practice -Fashion", Made in Italy Special Issue, Bloomsbury Publishing, London.

[3]. Bini, V. (2011), La Supply Chain Della Moda [Fashion Supply Chain], Franco Angeli, Milano. Birtchnell, T. and Urry, J. (2016), A New Industrial Future?: 3D Printing and the Reconfiguring of Production, Distribution, and Consumption, Routledge, London.

[4]. Buckley, C. (2011), "References to the past: the role of heritage and cultural values in fashion branding", Fashion and Luxury: Between Heritage and Innovation: the 13th Annual Conference for the International Foundation of Fashion Technology Institutes, Institut Français de la Mode, Paris, 11-16 April.

[5]. Berg, A., Hedrich, S., Lange, T., Magnus, K. and Mathews, B. (2017), "'The apparel sourcing caravan's next stop: digitization", McKinsey Apparel CPO Survey, McKinsey Apparel, Fashion Luxury Group, London.

[6]. Teunissen, J. and Van der Voet, H. (2013), "Fashion Technology and the smartphone' in Teunissen, José and Brand", J. Couturegraphique, Terralannoo/MOTI, Breda. pp. 183-193.

[7]. K. Straker, C. Wrigley, M. Rosemann The role of design in the future of digital channels: Conceptual insights and future research directions J. Retail. Consum. Serv., 26 (2015), pp. 133-140.

[8]. Barnes, L., \& Lea-Greenwood, G. (2006). Fast fashioning the supply chain: shaping the research agenda. Journal of Fashion Marketing and Management, 10, 259 - 271.

[9]. Bruce, M., Daly, L., \& Towers, N. (2004). Lean or agile: a solution of supply chain management in the textiles and clothing industry? International Journal of Operations and Production Management, 24, 15170.

[10]. Christopher, M., \& Towill, D. (2001). An Integrated Model for the Design of Agile Supply Chains. International Journal of Physical Distribution and Logistics Management, 31, 235-246.

[11]. Christopher, M., Lowson, R. \& Peck, H. (2004). Creating agile supply chains in the fashion industry.
International Journal of Retail and Distribution Management, 32, 367-376.

[12]. Cholachatpinyo, A., Fletcher, B., Padgett, I. \& Crocker, M. (2002). A. conceptual model of the fashion process - part 1: The fashion transformation process model. Journal of Fashion Marketing and Management, 6, 11-23.

[13]. Doeringer, P., \& Crean, S. (2006). Can fast fashion save the U.S. apparel industry? Socio-Economic Review, 4, 353-377.

[14]. Fernie, J., \& Azuma, N. (2004). The changing nature of Japanese fashion. Can quick response improve supply chain efficiency? European Journal of Marketing, 38, 749-69.

[15]. Runfola, A., \& Guercini, S. (2013). Fast fashion companies coping with internationalization: driving the change or changing the model? Journal of Fashion Marketing and Management, 17, 190-205.

[16]. Sheridan, M., Moore, C., \& Nobbs, K. (2006). Fast fashion requires fast marketing: The role of category management in fast fashion positioning. Journal of Fashion Marketing and Management, 10, 301 - 315 